\title{
Computational Thermal Studies for Transport Properties on Protonic Ceramic Fuel Cell
}

\author{
A. M. Seiden ${ }^{1}$, M. M. Kamal ${ }^{1}$, M. S. Al-Kotb ${ }^{2 *}$ \\ ${ }^{1}$ Department of Mechanical Power Engineering, Faculty of Engineering, Ain Shams University, \\ Cairo-11517, Egypt. \\ ${ }^{2}$ Department of Physics, Faculty of Science, Ain Shams University, \\ Cairo-11566, Egypt.
}

[*] Corresponding author: msalkotb@aucegypt.edu

In this paper, a mathematical model focuses on studying the thermal management and its effect on cell performance using a set of equations including electrochemical kinetics and thermodynamics governing the operation of a protonic ceramic fuel cell (PCFC). The model presents an approach to predict the behavior of the mass transport of gases through the $P C F C$ and the impact of optimizing the reactants flow rates will be useful for the water and exhaust gases management program for the cell. Additionally, the fuel cell energy balance is formulated in order to properly design a balanced system of PCFC. Moreover, the pressure drop across the flow channels is discussed as a crucial parameter affecting the fuel cell performance. The supplied air excess ratio and operating temperature impacts on the PCFC performance are investigated. The overall performance of PCFC systems is significantly influenced by ohmic, concentration, and activation polarizations. The modeling simulation results agreed satisfactorily with the experimental results from literature.

\section{Introduction:}

Increased greenhouse gas emissions from fossil fuels have led to climate changes that have negatively affected life on Earth, so new technologies that can produce and use energy more efficiently and cleanly than conventional combustion engines are urgently needed [1]. Fuel cells are one of those new technologies that can potentially play an important role in producing clean energy for sustainable human development [1]. Since Mr. Henry David announced the principle of reverse electrolysis in the early nineteenth century, the fuel cell has gone through a lot of development to improve its efficiency [2-4]. The fuel cell is an electrochemical device that converts hydrogen and oxygen into water and electricity, which are promising devices for converting renewable energy with low environmental impact. Also, the energy pathway in the fuel cell during 
energy conversion is much simpler and shorter than conventional power systems. Fuel cells are used in large-scale applications, such as transportation, stationary power plants, small power generation, etc. Transport markets around the world have shown significant interest in fuel cells. Almost all vehicle manufacturers and energy providers support their development [1].

Currently, there are six common types of fuel cells, such as alkaline fuel cell (AFC), phosphoric acid fuel cell (PAFC), solid oxide fuel cell (SOFC), molten carbonate fuel cell (MCFC), and protonic ceramic fuel cell (PCFC). Fuel cells are often classified according to the type of electrolyte, which consequently gives the operating temperature range of the fuel cell. Some fuel cells are classified by the type of fuel as direct methanol fuel cells (DMFC), and direct carbon fuel cells (DCFC). The PCFCs are receiving remarkable attention due to their great importance in energy conversion and, electrochemical sensors, storage applications, and separation membranes. Furthermore, PCFC is operating at relatively lower temperatures $\left(\sim 400-600{ }^{\circ} \mathrm{C}\right)$ by selectively transporting protons, since the small, singly charged protons require lower activation energy for transport than the large doubly-charged oxygen ions.

As a part of our modelling study of the, Proton we thought it would be fruitful to intensively study the effects of the supply and exhaust mass transport, also the heat transfer and temperature management for the PCFC system. All of those factors will be condensed and represented as the parameters affecting the supposed smooth quick start up and shut down phases.

While there have been numerous studies on the mass and heat transfer within the fuel cell, only few have mentioned the effect of managing mass and heat transfer regimes on the fuel cell system. Sordi et al. [1] presented a model to simulate a small scale fuel cell system for power generation fueled by biomass. The methodology studied the electrochemical and thermodynamic feature of a SOFC, besides solving the chemical equilibrium in the system. In this case the system and exergetic efficiencies were investigated by studying the chemical compositions, mass flows and temperatures at each point of the system. Milewski [2] introduced a 0-D model collecting the electrochemical, thermal, electrical, and flow, as a global approach to issues related to the work of SOFC, with concentrating on the fuel utilization factor and the Area Specific Internal Resistance. Navasa [3] introduced a pure heat studying model showing the different heat sources and sinks that contribute to the SOFC energy balance due to the chemical reactions that take place within the cell. Chan et al. [4] proposed a complete polarization model of a SOFC that using the Butler-Volmer equation to study the activation polarization and the considering both ordinary and Knudsen diffusions in studying the concentration polarization, while the ohmic polarization was slightly mentioned. This study showed the effect of the thickness of the fuel cell components on the drop in cell voltage. Liu et al. [5] completed a one- 
dimensional analytical for a PCFC in order to study the cell performance and optimize the flow channels design, where it was found that the fuel cell power density can be higher due to a smaller ratio of the width of channel rib/wall against the total width. This type of researches can only be considered a first step towards a wider understanding of the fuel cell stack performance, with an exclusive focus on the thermodynamic and electrochemical approaches defining the main voltage polarization equations, without considering the phases of mass and heat transport within the cell, as well as, the changes within the flow channels.

Indeed, understanding the impact of all variables allows fuel cells innovators to optimize their design of the modular units, and it also allows engineers to boost the system performance for cost-effective applications.

\section{Computational Procedures}

The computational procedures follow a particular orders and commands, which is sketched as a flowchart in Fig. (1). The developed model designed to estimate electrolytic and electronic properties of proton-conducting electrolytes in fuel cell mode and establish which parameters affect their transport properties. The activation polarization is given by the Butler-Volmer equation, as given in Ref. [5], the transfer coefficient is typically set as 0.5 , and the number of electrons flow through the external circuit for every mole of fuel oxidation is 2 . The iterative processes are obligatory to preserve the calculation processes continuously and achieve the desired evaluation precision, it is important to construct a correct convergence criterion.

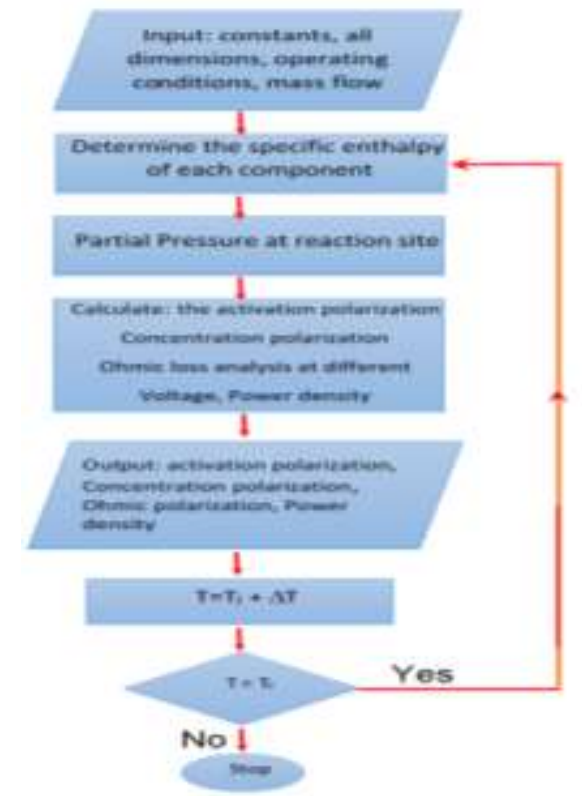

Fig. (1): Flowchart of the Developed Model. 


\section{PCFC Energy Balance:}

In order to properly design a fuel cell, we have to determine the basic inputs, outputs and losses within the fuel cell. A procedure of formulating the energy balance for the fuel cell needs to be created for the system, as shown in Fig. (2) [6].

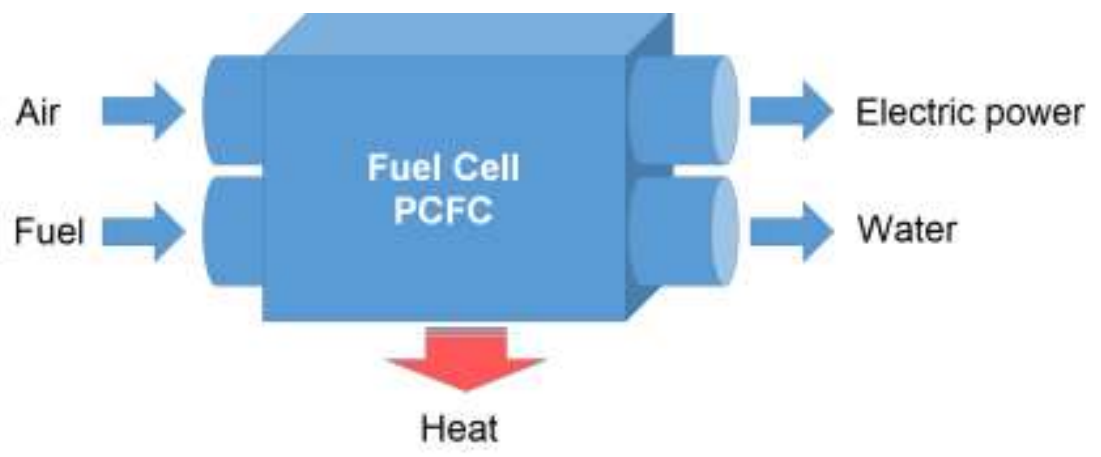

Fig. (2): Fuel Cell Energy Balance.

As known for all energy conversion systems, there is an ideal (reversible) case, and a real (irreversible) one. Under thermodynamically reversible condition, a fuel cell can achieve maximum theoretical electrical energy output $\left(W_{e l}\right)$, which is related to the Gibbs free energy of the process $(\Delta G):[7]$.

$$
W_{e l}=\Delta G
$$

and from the second law of thermodynamics:

$$
W_{e l}=\Delta G=\Delta H-T \Delta S
$$

where the enthalpy change $(\Delta H)$ is the total available thermal energy, $T$ is the absolute temperature and $\Delta S$ is the entropy change. So the free energy available $(\Delta G)$ equals the total thermal energy $(\Delta H)$ available in the system minus the amount of heat produced by the system operating reversibly $(T \Delta S)$. [7]

Since the thermal efficiency of the system is defined as the maximum useful energy produced relative to the available heat content, then the fuel cell thermal efficiency can be calculated using Eq. (3), which is 0.83 for most of the fuel cells. [8].

$$
\eta_{\text {ideal }}=\frac{\Delta \mathrm{G}}{\Delta \mathrm{H}}
$$

The general energy balance is mainly based on the processes of energy absorption and releasing. So, the energy balance states that the enthalpy of reactants equals the enthalpy of products plus the power output; heat generated and heat loss from the system to the surroundings. $[6,9]$. 
Eq. (4) represents the PCFC overall reaction including the internal reforming and water gas shift reactions:

$$
\mathrm{C}_{a} \mathrm{H}_{b}+\frac{a}{2} \mathrm{O}_{2}+a \mathrm{H}_{2} \mathrm{O} \rightarrow a \mathrm{CO}_{2}+\left(a+\frac{b}{2}\right) \mathrm{H}_{2}
$$

Therefore, the generic energy balance equation for the PCFC will be : [6]

$$
\frac{W_{e l}}{m_{\text {fuel }}}+\frac{Q}{m_{\text {fuel }}}+a h_{\mathrm{CO} 2}=h_{\text {fuel }}+\frac{a}{2} h_{O 2}+a h_{H 2 O}
$$

The enthalpy $(h)$ for dry gases can be calculated using Eq. (6) : [11]

$$
h=m * C_{p} * T
$$

where $m$ is mass flow rate, $T$ is temperature and $C_{p}$ is specific heat.

While enthalpy for water vapour will be according to Eq. (7)

$$
h=\left(m_{\mathrm{H} 2 \mathrm{O}_{\mathrm{gas}}} * C_{p_{\mathrm{H} 2 \mathrm{O}_{\mathrm{gas}}}} * T\right)+\mathrm{h}_{\mathrm{fg}}
$$

where $h_{f g}$ is latent heat of vaporization.

\section{Heat Transfer Study through PCFC:}

In PCFC system, heat is exchanged in many ways through the system's processes. Heat transfer consists of convection, conduction and radiation. Convection happens between the solid surfaces and the flowing gases. Conduction occurs in the solid and porous structures. Additionally, radiation arises from the fuel cell to the surroundings [12]. On the other hand, the heat released can be used in a cogeneration system such as a gas turbine.

\subsection{Natural Heat Dissipation}

Regarding the heat dissipation phase, it is not of a great importance in case of a single cell PCFC, where heat dissipation is greater than generation, due to large surface area [13]. For a stack of cells, effective heat dissipation can represent an issue and thermal management solutions should be provided. Heat produced in the fuel cell as a result of the various chemical reactions listed above is dissipated via combined convection and radiation heat transfer which can be formulated as:

$$
Q_{\text {dis }}=\frac{T_{s t}-T_{0}}{R_{\text {th }}}
$$

where $T_{s t}$ is the stack surface temperature, $T_{o}$ is the surroundings temperature and $R_{t h}$ is the thermal resistance, which can be expressed as follows:

$$
R_{\mathrm{th}}=\frac{1}{\frac{1}{R_{C}}+\frac{1}{R_{R}}}
$$

where $R_{C}$ is convective thermal resistance and $R_{R}$ is radiation thermal resistance. 


\subsection{Stack Heat Management}

Proper heat management is an essential tool to ensure that the fuel cell system runs unfailingly. Cooling can be achieved through various means. Passive cooling can be achieved with heat sinks and cooling fins, which is more suitable for small sized fuels cells. While active cooling with fluid coolants can be used to transfer heat by heat exchangers as represented in Fig. (3), which is a practical solution for large size stacks.

One way of stack cooling is using a heat exchanger, which allows the stack to operate at higher temperatures. Eq. (9) shows the basic heat exchanger equations.

$$
Q_{\text {cool }}=m_{\text {cool }} * C_{\text {cool }} *\left(T_{\text {cool, out }} * T_{\text {cool, in }}\right)
$$

where $m_{\text {cool }}$ is the coolant mass flow rate, $C_{\text {cool }}$ is coolant specific heat capacity, and $T_{\text {cool }}$ is the coolant temperature. [14]

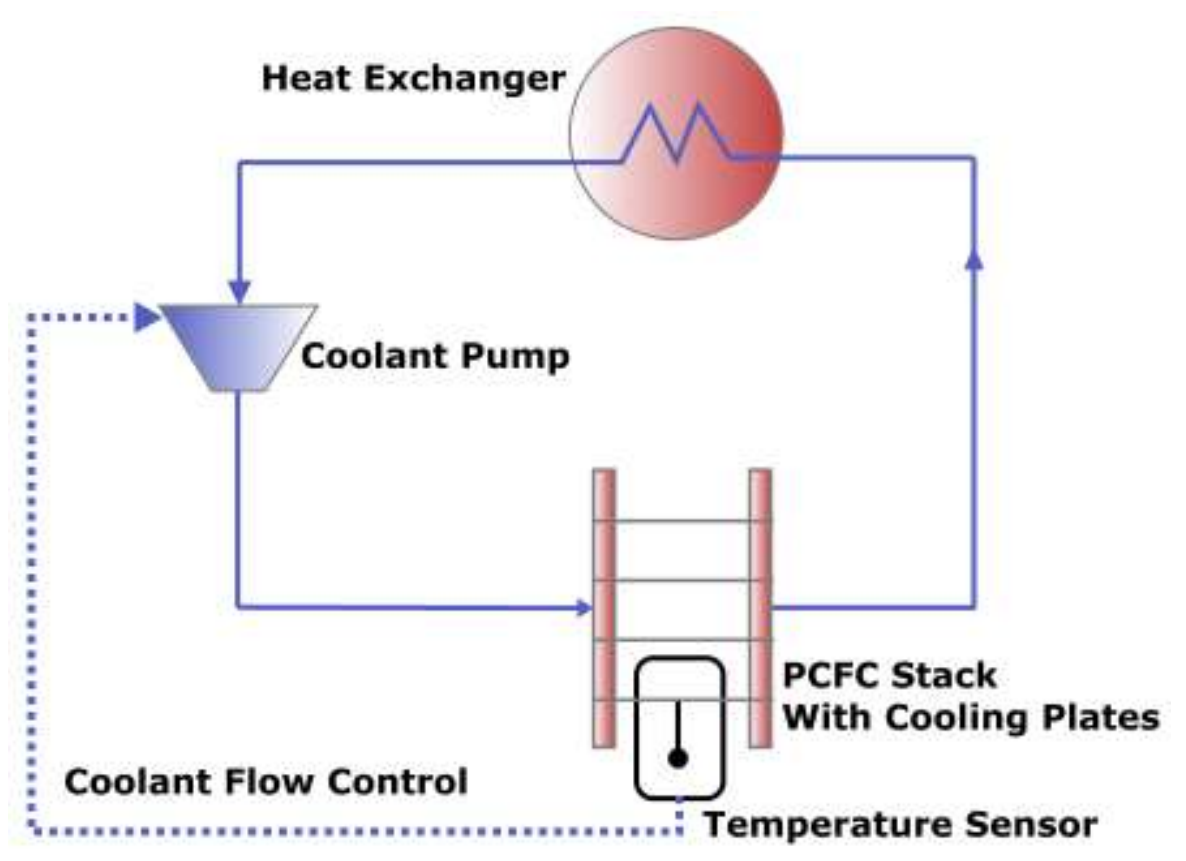

Fig. (3): PCFC Heat Management.

\section{Mass Balance through PCFC}

When designing a fuel cell, mass flow rates must be calculated; to assure best performance can be achieved by the system. The supply flow rates of the reactants must be greater than their consumption rate within the system, which depends mainly on the fuel cell size. Air is often supplied at a rate higher than the 
stoichiometric ( 2 or higher), due to the slow reaction rate at the cathode. Also, when using hydrocarbon based fuel, the fuel supply rate should be slightly higher than the stoichiometric (from 1.2 to 1.5 ), to be able to extract the suitable amount of hydrogen needed. [6, 11].

Hereunder we will introduce a sequence of equations defining the mass flow rates calculations for both the supply and exhaust parts within the PCFC. All mass flow rates will be introduced in terms of $\mathrm{g} / \mathrm{s}$. $[6,11]$

Since the PCFC system must obey the law of mass conservation:

$$
\sum m_{\text {in }}=\sum m_{\text {out }}
$$

then we should divide our calculation into two parts: supplied gases and exhaust gases.

\subsection{Supplied Gases:}

\subsubsection{Hydrogen mass flow rate:}

$$
m_{H_{2} \text { in }}=S_{\text {fuel }} * \frac{M_{H_{2}}}{2 f} * I
$$

where $S_{f u e l}$ is the supplied fuel stoichiometric ratio, $X_{H 2}$ is the hydrogen molar fraction, $M_{H_{2}}$ is the hydrogen molecular weight and $\mathrm{I}$ is the electric current.

\subsubsection{Oxygen mass flow rate:}

$$
m_{\mathrm{O}_{\text {in }}}=S_{\text {air }} * \frac{M_{\mathrm{O}_{2}}}{4 f} * I
$$

where $S_{a i r}$ is the supplied air excess ratio, $X_{O 2}$ is the oxygen molar fraction $(21 \%), M_{O 2}$ is the oxygen molecular weight.

\subsubsection{Air mass flow rate:}

$$
m_{\text {air }}=\frac{S_{\text {air }}}{X_{\mathrm{O}_{2}}} * \frac{M_{\text {air }}}{4 f} * I
$$

where $X_{O 2}$ is the oxygen molar fraction $(21 \%), M_{\text {air }}$ is the air molecular weight.

\subsubsection{Steam mass flow rate at anode side:}

Steam needed for the steam direct reforming process is in order of 4.5 grams per gram $\mathrm{H}_{2}$. [15]

\subsubsection{Water vapor mass flow rate at cathode side:}

For humid air, the amount of $\mathrm{H}_{2} \mathrm{O}$ in the air inlet stream can be calculated using Eq. (14) 


$$
m_{H 2 O_{i n_{c a}}}=\frac{S_{a i r}}{X_{O_{2}}} * \frac{M_{H 2 O}}{4 f} * \frac{\theta_{c a} * P_{v s} T_{c a} \text { in }}{P_{c a}-\theta_{c a} * P_{v s} \tau_{c a} \text { in }} * I
$$

where $\theta_{c a}$ is the supply air relative humidity, $P_{c a}$ is supply air pressure and $P_{v s} T_{c a, i n}$ is water vapour saturation pressure, which can be calculated using Eq. (15): [16]

$$
P_{v S}=610.75 * e^{\frac{T-273}{T-34.7}} * 17.2694
$$

\subsection{Supplied Gases:}

\subsubsection{Anode side residual gases:}

$$
m_{a n_{\text {out }}}=m_{a n_{\text {in }}}-\frac{M_{H 2}}{2 f} * I
$$

where $m_{a n, i n}$ is the hydrocarbon fuel supply rate.

\subsubsection{Depleted air from cathode side:}

$$
m_{\text {air }}=m_{\text {air }}-\frac{M_{O 2}}{4 f} * I
$$

\subsubsection{Water vapor at anode side exit:}

$$
m_{H 2 O_{\text {out }} a n}=m_{a n_{\text {out }}} * \frac{P_{v s} \tau_{a n, \text { out }}}{P_{a n}-\Delta P_{a n}-P_{v s} \tau_{a n} \text { out }}
$$

where $\Delta P$ is the pressure drop.

\subsubsection{Water vapor at cathode side exit:}

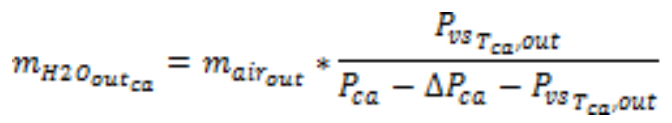

\section{Pressure Drop through Flow Channels}

Reactant gases pressure is a crucial parameter as it may affect other parameters within the PCFC such as diffusivity, molar composition and density. Fuel cells can either operate at atmospheric pressure or in a pressurized condition. While fuel cells can perform better with increasing pressure, the need of pressurization may decrease the overall system efficiency, and also affects the 
water management system [6]. It has also been noted that high pressure operation may cause brittleness of the PCFC materials [18]. But even at system operating at atmospheric pressure, the inlet gases pressures must be slightly higher than the desired pressure; to be able to overcome the pressure drop in the flow channels, which affects the rate and consistency of mass transport. In this model, an arrangement of parallel flow channels is used as shown in Fig. (4), so the pressure drop across a single channel is also the pressure drop across the whole flow channels [17]. The gas moves by mean velocity from one end of the channel to another, the pressure drop is the flow pressure difference between the two ends. Since the flow is assumed to be incompressible, then the pressure drop can be calculated using Eq. (20): [6].

$$
\Delta P=\frac{f r * L_{c h}}{d_{H}} * \rho * \frac{V_{m}^{2}}{2}+\rho * \frac{V_{m}^{2}}{2}
$$

where $f r$ is the friction factor, $L_{c h}$ is the channel length, $d_{H}$ is hydraulic diameter, $\rho$ is the fluid density, $V_{m}$ is the mean velocity.

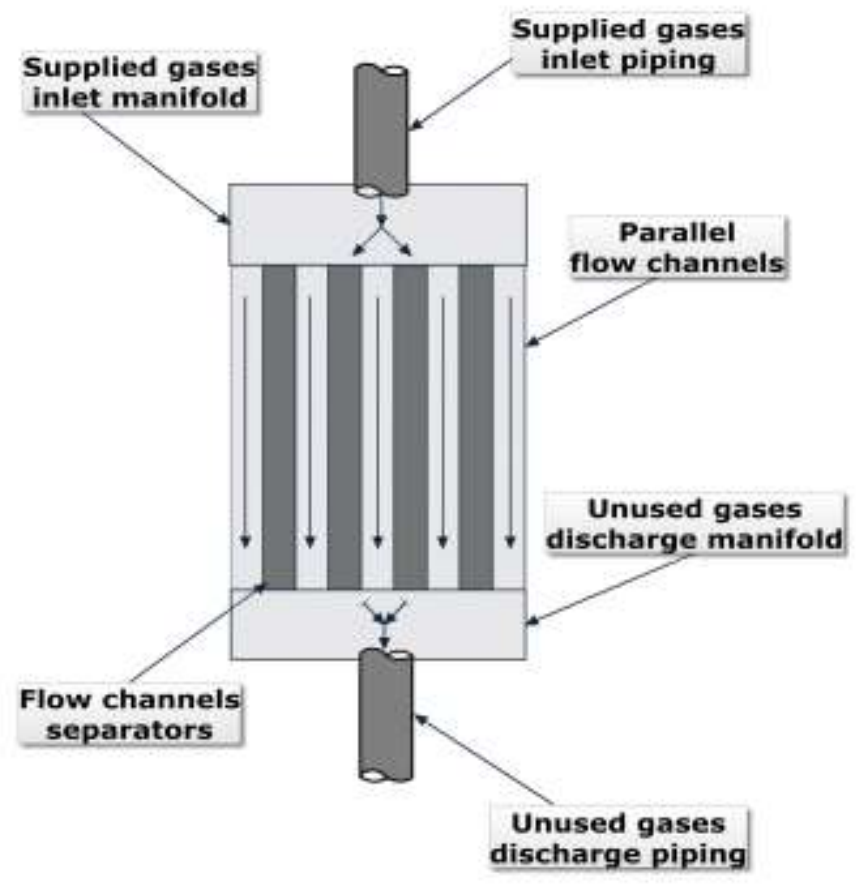

Fig. (4): Fuel Cell Parallel Flow Channels.

To simplify the calculation of the friction factor $(f r)$, we should determine first whether the flow is laminar or turbulent. This can be attained by calculation the Reynolds number (Rey): 


$$
\text { Rey }=\frac{V_{m} * \rho * d_{H}}{\mu}
$$

where $\mu$ is the fluid dynamic viscosity.

and as found in the literature [6] that regardless the velocity or channel geometry, a relationship for rectangular channel can be simplified as:

$$
f r=\frac{55+41.5 * e^{-\frac{3.4}{w_{c} / d_{c}}}}{R e y}
$$

where $w_{c}$ is the channel width and $d_{c}$ is the channel depth.

\section{Results Analysis and Discussion:}

Since PCFCs can generally operate under various operating conditions; this section presents a performance analysis of the planar PCFC with respect to key operating parameters under isothermal conditions, in an attempt to find an optimum operating scenario for the PCFC.

\subsection{Impact of Operating Temperature:}

For high and intermediate temperature fuel cells, operating temperature is a crucial parameter that not only affects its performance, but also the cost and lifetime of the system. Fig. (5) shows that the ohmic polarization decreases obviously with increasing temperature, because protonic conductivity is very sensitive to temperature. In the same way, Fig. (6) shows that the activation polarization decreases by increasing the temperature. This is attributed to the fact that the higher the temperature leads the more reactive the electrodes become; and consequently, the easier it is for the charge to overcome the activation energy barrier. On the other hand, Fig. (7) shows that the concentration polarization increases with temperature. When the temperature is increased, the density of the reactant gases decreases; therefore, the molar diffusion rate decreases [18]. As a result, the net magnitude of the overpotentials will decrease.

As presented in Fig. (8) and Fig. (9), a higher cell actual voltage and higher power density can be achieved at higher temperatures of the system. Accordingly, a balance between these conflicting aspects should be sought when selecting the optimum operation temperature. It is worth noting that there are additional parameters that may be affected by the temperature. For example, operating at a lower temperature subjects the fuel cell to lower thermal stresses and shorter system warm up times, which directly affect the initial and running costs of the system. However, the current model does not consider those additional factors hence care should be taken when selecting the optimum operation temperature. The experimental studies in the reference reported operation temperatures of the PCFC up to $1100 \mathrm{~K}$. 


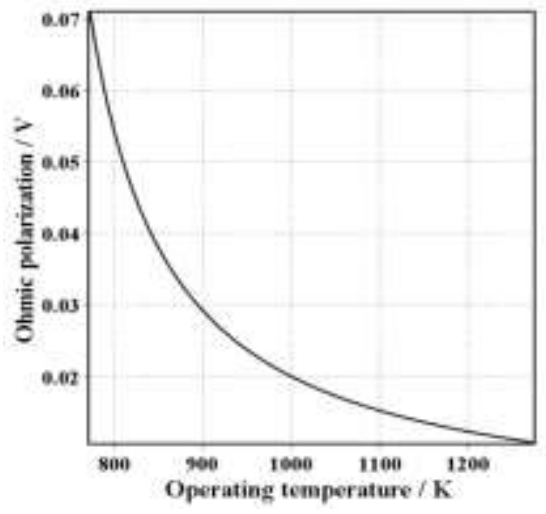

Fig. (5): $V_{\text {ohm }}$ in variation with $T$.

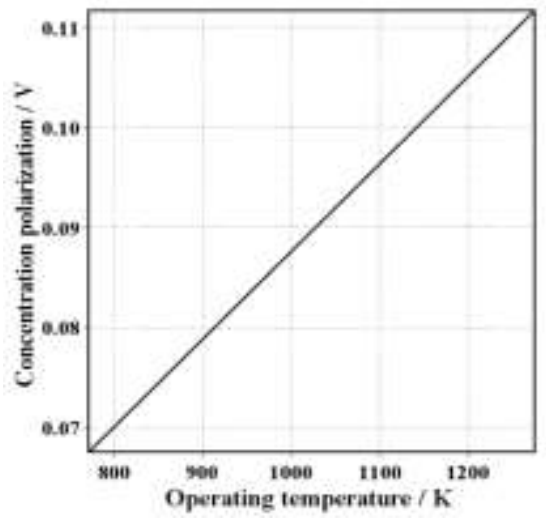

Fig. (7): $V_{\text {conc }}$ in variation with $T$.

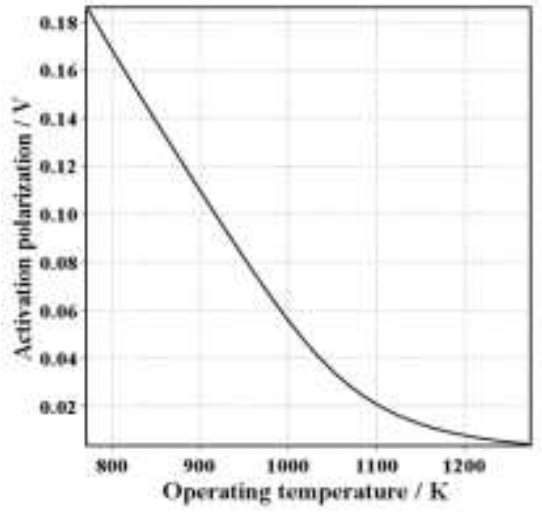

Fig. (6): $V_{\text {act }}$ in variation with $T$.

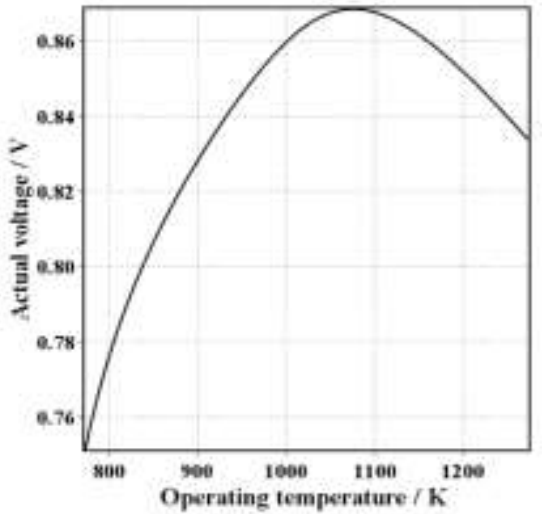

Fig. (8): $\mathrm{E}$ in variation with $\mathrm{T}$.

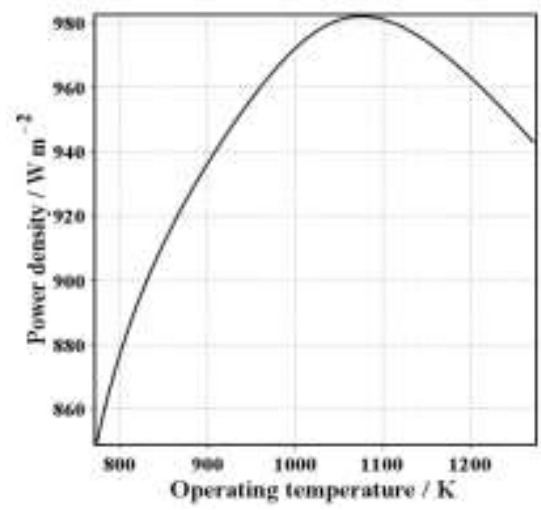

Fig. (9): $\mathrm{P}$ in variation with $\mathrm{T}$.

\subsection{Impact of Excess Air Ratio}

Air is often supplied at a higher stoichiometric rate, due to the slower reaction rate at the cathode side. So in order to maintain high concentration of oxygen, we have to supply excess air, which can be two or more of the stoichiometric ratio [6]. Other important reason for supplying excess air is to 
ensure the stability of oxygen stability regardless the mixing of water vapour generated at the cathode side with air [19]. Additionally, excess air helps pushing that generated water vapour out of the PCFC [20]. On the other hand, air has to be added in cautious measures, as it can result in an explosive mixture with hydrogen [21]. Moreover, excess air can lower the cell average temperature which can dramatically decrease the cell performance [22].

On a general basis, by increasing the excess air ratio; the power density slightly decreases (Fig. (9)), which is validated using the experimental results from the literature [23]. Regarding the activation and ohmic over potentials, changing the excess air ratio has no great effect. Concentration over potential happens to slightly increase with increasing excess air ratio.

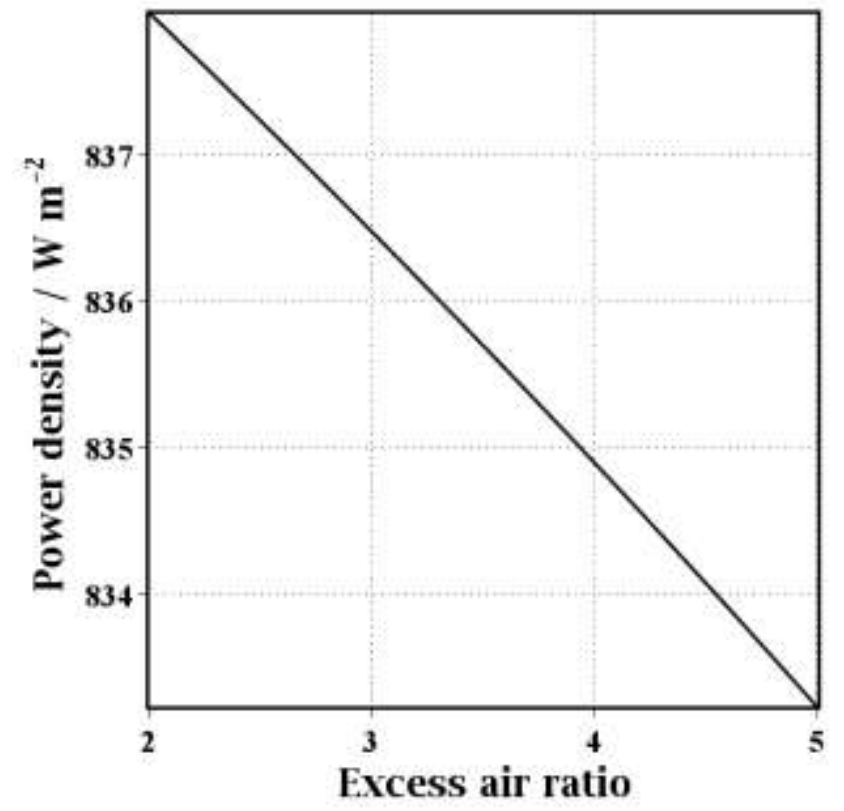

Fig. (9): Power density in variation with the excess air ratio.

\section{Conclusion}

Using our developed mechanistic mathematical model describing the PCFC performance and design parameters, this paper tries to present an approach to predict the behavior of the mass transports through the PCFC. Also, the heat transport regimes, as a way to comprehend the heat management for the PCFC. A procedure for formulating the fuel cell energy balance was discussed, to be able to properly design a balanced system. The net conclusion is that as the operating temperature increases the current density and power density of the PCFC. However, the maximum possible temperature should be limited by the induced thermal stresses which affect the cost and lifespan of the fuel cell. With regards to 
the excess air ratio, generally, excess air is highly needed to maintain high oxygen concentration and pushing out generated water at the cathode; even so, increasing the ratio of excess air decreases the performance of the PCFC by decreasing the average cell temperature. Accordingly, the fuel cell operating conditions must be investigated from a system perspective; hence, a balance should be made between the boosting of the electrochemical performance and the overall system efficiency.

This model determines such important parameters as maximal power density; ohmic and polarization resistances; average ion transport numbers; and their activation energies.Further, the main limitation of the current model is related to that some issues were not taken into account, such as the thermal and mechanical stresses. These are major issues for a stack of cells, and are should be taken into consideration as an expansion of the current model.

\section{References:}

1. A. Sordi, E. Silva, A. J. M. Neto, D. G. Lopes, C. Silva Pinto, P. D. Araújo, Brazilian Journal of Chemical Engineering, 26, 745, (2009).

2. J. Milewski, Fuel Cells, 12, 709, (2012).

3. M. Navasa, Lund University, Sweden, (2012).

4. S. H. Chan, K. A. Khor, Z. T. Xia, Journal of Power Sources, 93, 130 (2001).

5. H. Liu, Z. Akhtar, P. Li, K. Wang, Energies, 7, 173 (2014).

6. C. Spiegel, Designing and Building Fuel Cells, 1st ed., McGraw-Hill, New York, 2007.

7. D. B. J. T. M. Koehler, L. J. Bond, Pacific Northwest National LaboratoryUnited States Department of Energy, USA, (2001).

8. M. Kuhn, T. Napporn, Energies, 3, 57, (2010).

9. E. G. T. Services, Fuel Cell Handbook, 7th ed., National Energy Technology Laboratory, Morgantown, West Virginia, (2004).

10. D. R Stull, H. Prophet, JANAF Thermochemical Tables, Second ed., National Bureau of Standards U.S, USA, (1971).

11. A. Kabza, (2015).

12. X. Xue, J. Tang, N. Sammes, Y. Du, Journal of Power Sources, 142, 211 (2005).

13. F. Barbir, A. Boston, H. London, N. York, O. Paris San, D. San, F. Singapore, S. Tokyo, PEM Fuel Cells : Theory and Practice, Elsevier, England, (2005).

14. T. L. Bergman, D. P. DeWitt, F. Incropera, A. S. Lavine, Fundamentals of Heat and Mass Transfer, Vol. 997, John Wiley \& Sons, Inc., New Jersey, (2011). 
15. J. L. Andrew Dicks, Fuel Cell Systems Explained, Second Edition ed., SAE International and John Wiley \& Sons, Ltd., England, (2003).

16. K. G. B. K. Ravi Kumar, S. Udaya Bhaskar International Journal of Advanced Research in Engineering and Technology (IJARET), 4, 178 (2013).

17. P. H. Lee, S. S. Hwang, Sensors, 9, 9104 (2009).

18. M. Ni, M. K. H. Leung, D. Y. C. Leung, Energy Conversion and Management, 48, 1525 (2007).

19. S. Wang, J.-L. Luo, A. R. Sanger, K. T. Chuang, The Journal of Physical Chemistry C, 111, 5069 (2007).

20. B. Lin, Journal of Power Sources, 86, 202, (2000).

21. N. Sammes, Fuel cell technology-reaching towards commercialization, (2006).

22. V. M. Janardhanan, V. Heuveline, O. Deutschmann, Journal of Power Sources, 172, 296 (2007).

23. J. Cieslinski, T. Kaczmarczyk, B. Dawidowicz, Performance of the PEM fuel cell module. Part 2. Effect of excess ratio and stack temperature, Vol. 97, (2017). 